\title{
Drivers to adopting B-flow ultrasonography:contextualizing the integrated technology acceptance model
}

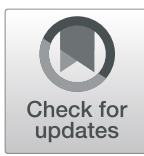

\author{
Gulsah Hancerliogullari Koksalmis ${ }^{1,2}$ D
}

\begin{abstract}
Background: Ovarian torsion is an unprecedented gynecological crisis that regularly influences ladies of regenerative age. Its signs and indications are like those of other abdominal conditions, which make its differential determination testing. B-flow ultrasonography (B-flow USG), which is utilized for the differential determination of ovarian torsion, is the highest quality level non-intrusive indicative instrument in the early period of an ovarian torsion. The aim of this paper is to investigate and incorporate variety of factors affecting physicians' actual use of B-flow USG.

Methods: Drawing from technology acceptance model (TAM), five variables - actual use, behavioral intention to use, attitude toward use, perceived ease of use and perceived usefulness - are integrated with social influence and knowledge to propose a theoretical model. The data was collected from the medical doctors including radiologists, urologists, gynecologists, pediatric surgeons between June and October 2018. The sample size is $N=512$ hence, structural equation modeling (SEM) methodology has been implemented to study the relationship between explanatory factors and actual use of B-flow USG. SmartPLS 3.2.7 software was used for the data analysis and testing of the validity of the eight hypotheses.
\end{abstract}

Results: The results indicate that actual use of B-flow USG is positively affected by knowledge, social influence, perceived ease of use, perceived usefulness, attitude toward use and behavioral intention to use.

Conclusions: It is discovered that perceived usefulness mediates the relationship between perceived ease of use and attitude toward use, and attitude toward use mediates the relationship between perceived usefulness and behavioral intention to use B-flow USG. The implications of the outcomes are discussed, and suggestions for future research are made.

Keywords: Ovarian torsion, B-flow ultrasonography (B-flow USG), Technology acceptance model, Knowledge, Social influence

\section{Background}

Ovarian torsion is a surprising gynecological crisis that comprises around $2.7 \%$ of the gynecologic protestations in regenerative age ladies [1-3]. The most well-known reasons for ovarian torsion, which happens because of the turn of the pedicle of the ovarian tissue, are irritation and injury [3]. Ovarian torsion regularly gives nonspecific manifestations, including abdominal torment,

\footnotetext{
Correspondence: ghancerliogullari@itu.edu.tr

${ }^{1}$ Department of Industrial Engineering, Faculty of Management, Istanbul Technical University, Istanbul, Turkey

${ }^{2}$ School of Management, Centre of Operational Research, Management Sciences \& Information Systems, University of Southampton, Southampton, UK
}

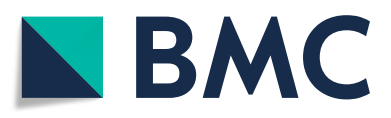

(c) The Author(s). 2019 Open Access This article is distributed under the terms of the Creative Commons Attribution 4.0 International License (http://creativecommons.org/licenses/by/4.0/), which permits unrestricted use, distribution, and reproduction in any medium, provided you give appropriate credit to the original author(s) and the source, provide a link to the Creative Commons license, and indicate if changes were made. The Creative Commons Public Domain Dedication waiver (http://creativecommons.org/publicdomain/zero/1.0/) applies to the data made available in this article, unless otherwise stated. spasms, testiness, loss of craving and hot flashes [2, 4]. In view of these nonspecific manifestations, the differential finding of the infection from other abdominal conditions is testing. Past investigations have announced that exploratory laparotomy, which is regularly performed dependent on preservationist demonstrative techniques, has a $56 \%$ false conclusion rate [4]. Numerous investigations have detailed that an exact conclusion must be made by visual finding amid an obtrusive laparoscopy or laparotomy [2]. With the ongoing advances in the innovation, the utilization of non-intrusive analytic apparatuses is obligatory. What's more, it is vital to assess the pedicle blood flow and blood divider structure for 
the conclusion of the infection with the end goal to counteract superfluous medical procedure. While color Doppler USG has been generally utilized for the differential finding of ovarian torsion throughout the previous 2 years, the as of late presented B-flow ultrasonography imaging framework seems to conquer the challenges in the assessment of blood flow and divider thickness. Bflow is another strategy that expands the goals, outline rate and dynamic scope of B-mode to at the same time picture blood flow and tissue [5-7].

Despite the increasing usage of B-flow USG, research on actual use of B-flow USG is scarce. The aim of this empirical study is to fill this gap by exploring the acceptance of B-flow USG, and various factors that affect physicians' preference of B-flow USG use. None of the empirical research takes into account both drivers and barriers to predict user intention to adopt B-flow USG. So as to have a robust theoretical basis for investigating the acceptance of B-flow USG, this study draws on technology acceptance model which has been utilized in numerous researches to anticipate and find out user perception of system use.

The contributions of this study are fourfold. First, this study identifies which determinants are more effective in acceptance of B-flow USG use. No previous research demonstrates factors affecting the adoption of B-flow USG. Moreover, there has been no study where the constructs used in this model are modeled together to determine the determinants of actual use of B-flow USG. Second, there are few researches studied the determinants of actual use of medical systems; however, to the best of knowledge, the current research has the largest sample size with 528 participants and more than $97 \%$ of the responses were used in the analysis. Third, this study assesses if the incorporation of technology acceptance model supplies a robust theoretical basis for studying the acceptance of B-flow USG. This paper discovered two mediation effects: perceived usefulness mediates the relationship between perceived ease of use and attitude toward use, besides attitude toward use mediates the relationship between perceived usefulness and behavioral intention to use B-flow USG. Fourth, the results of this study prove that behavioral intention to use is significantly and directly associated to actual use of B-flow USG. Knowledge, social influence, perceived ease of use, perceived usefulness and attitude toward use also influence actual use of B-flow USG significantly and indirectly through behavioral intention to use. The results of the present study are of high relevance to stakeholders including B-flow USG users, hospital managements, manufacturers and suppliers. The target audience also involves business analysts and researchers who seek to comprehend the factors driving physicians to use B-flow USG and, hence, to make future forecasts of the imaging technology and its distribution.
The organization of the rest of the paper is as follows: In the second section theoretical background and hypotheses are provided. The research methodology is explained in the third section. Next, the results of the analysis are provided. The paper concludes with discussion of the findings, directions for future research and theoretical and practical implications.

\section{Theoretical background and hypotheses development}

The theoretical basis of this research consists of Technology Acceptance Model. So as to investigate the acceptance of a novel technology, B-flow USG, the integration of this model with knowledge and social influence is selected as a theoretical framework. The proposed research framework is shown in Fig. 1. There are 7 constructs, specifically, actual use, attitude toward use, behavioral intention to use, knowledge, perceived ease of use, perceived usefulness, social influence with 32 items. The hypotheses are developed based on the literature.

\section{Technology acceptance model}

The technology acceptance model is currently a common predictive tool for testing the users' acceptance of new technologies in various industries including healthcare, education, e-commerce, etc. [8]. TAM, which describes users' behavior towards information technology adoption, is a model emerging from theory of reasoned action (TRA) [9]. TAM consists of the following factors, i.e., constructs, which can be utilized to solve any technology acceptance problems: actual system use, behavioral intention to use, attitude towards use, perceived usefulness, perceived ease of use and external variables. According to TAM, which is an information systems theory, perceived usefulness (PU) and perceived ease of use (PEU) are the primary antecedents of intention to use information technology. Moreover, it was indicated that perceived ease of use influences perceived usefulness and attitude towards use; perceived usefulness affects both attitude towards use and behavioral intention to use; attitude towards use influence behavioral intention to use which determines actual system use.

\section{Actual use}

Actual use is a measure of the frequency and intensity of the use of information technology in an individual's work. The level of use of the new technology shows the use of the system and the acceptance of the technology. To get more benefits from the B-flow USG, surely the system usage needs to increase. So, this helps the physicians to achieve their goals for execution of B-flow USG [10].

\section{Behavioral intention to use}

Behavioral intention means "the degree to which a person has formulated conscious plans to perform or not 


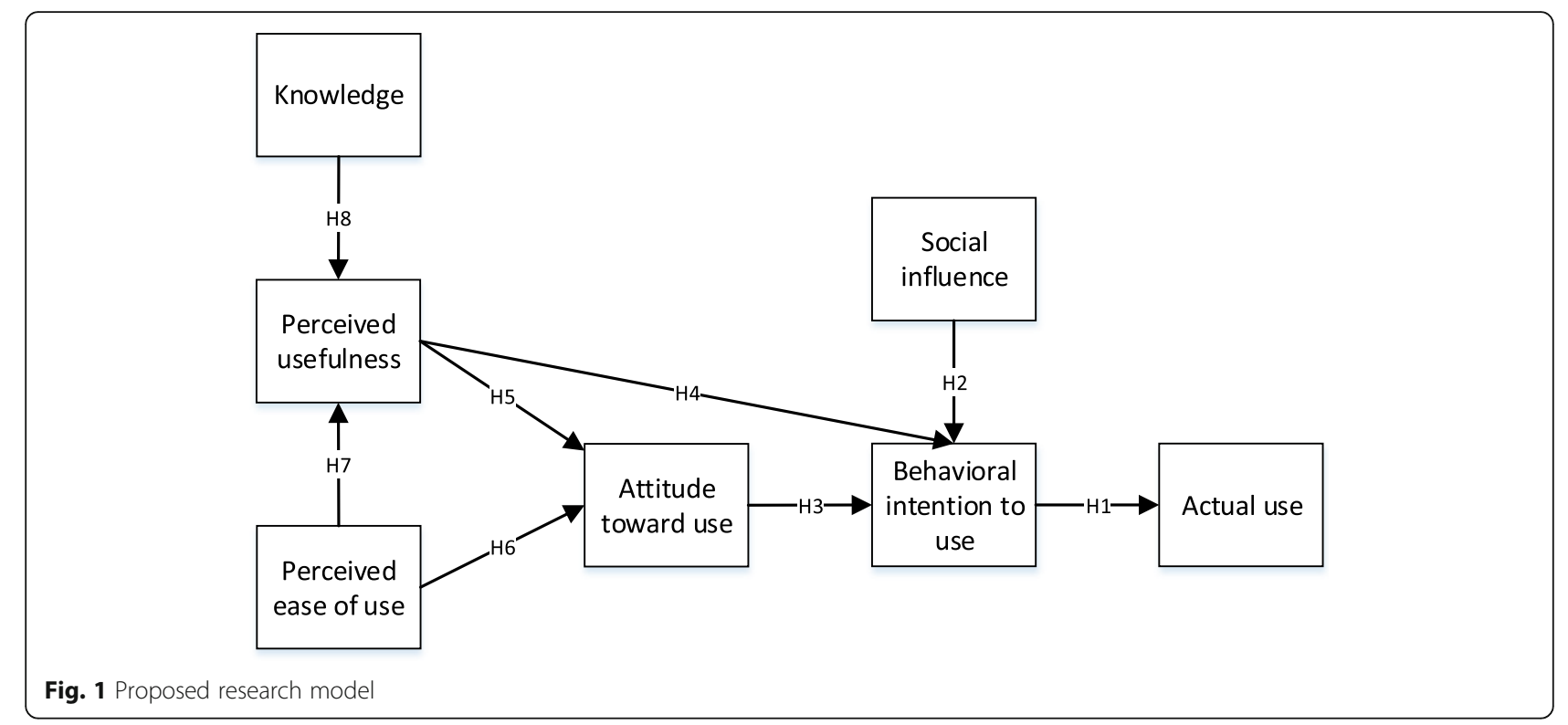

perform some specified future behavior" [11]. It is defined as "a behavioral tendency of people to keep using a certain technology" [8]. It is a determinant of the possibility that an individual will be engaged in a certain behavior [12]. The more a person is willing to use a system, the higher is his or her likelihood of using it [13]. In the current study, since the usage of B-flow USG is done of one's own fee will, finding out the determinants of behavioral intention to use B-flow USG is important for the actual use of it. Earlier work have described the impact of behavioral intention on actual use. As a result, it was hypothesized as follows:

\section{H1. Behavioral intention has a positive relationship with actual use of B-flow USG.}

\section{Social influence}

Social influence refers to "a person's perception that most people who are import to him think he should or should not perform the behavior in question" [14]. Social influence, which affects the behavioral intention directly is denoted as subjective norm in TRA and Extended TAM, and it is represented as social factors in Model of PC Utilization. Social influence is crucial merely in the initial periods of personal experimentation with the technology. It is indicated that social influence affects behavioral intention positively $[11,15]$. Users will intend to use B-flow USG if their families, friends and peers use it or recommend using it. As a result, it was hypothesized as follows:

H2. Social influence has a positive relationship with behavioral intention to use B-flow USG.

\section{Attitude toward use}

Attitude refers to "individual's positive or negative feelings about performing the target behavior" $[14,16]$. In other words, it is the person's behavior for a service or a product. Based on the TRA, behavioral intention to use is affected by the attitude toward behavior and subjective norms. In accordance with the TAM, perceived usefulness and attitude toward use determine the behavioral intention to use. Several researches have shown the impact of attitude toward use on behavioral intention to use, which is significant $[15,17-20]$. As a result, it was hypothesized as follows:

H3. Attitude toward use has a positive relationship with behavioral intention to use B-flow USG.

\section{Perceived usefulness}

Perceived usefulness is "the degree to which an individual believes that using a particular system would enhance his or her job performance" [8]. Put differently, it means that B-flow USG usage will improve the productivity of the user and ultimately result in being more efficient and accurate [21]. In the original technology acceptance model, perceived usefulness is a key factor affecting behavioral intention to use [16]. Several researches in various areas verifies the effect of perceived usefulness on the behavioral intention to use and attitude toward use $[18,22-24]$. Thus, in addition to various application areas, the effect of perceived usefulness on behavioral intention to use B-flow USG may be critical. As a result, it was hypothesized as follows:

H4. Perceived usefulness has a positive relationship with behavioral intention to use B-flow USG. 
In the original TAM, not only perceived usefulness but also perceived ease of use are affecting attitude toward use. Moreover, perceived usefulness and attitude toward use affect behavioral intention to use [8]. A user who thinks that B-flow USG usage improves his or her performance has an optimistic attitude toward use B-flow USG. Several research have demonstrated the positive and significant relationship between perceived usefulness and attitude toward use $[8,18,25,26]$. Hence, it was hypothesized as follows:

H5. Perceived usefulness has a positive relationship with attitude toward use B-flow USG.

\section{Perceived ease of use}

Perceived ease of use is "the degree to which a person believes that using a particular system would be free of effort" [8]. Alias, it is a sign of the intellectual strength necessary for learning and using an information system [27]. Both perceived usefulness and perceived ease of use are affecting attitude toward use in the original TAM. A user who thinks that using the B-flow USG would be easy has an optimistic attitude toward use Bflow USG. Therefore, it was hypothesized as follows:

\section{H6. Perceived ease of use has a positive relationship with attitude toward use B-flow USG.}

If all other factors are held constant, the easier the system, the higher the user's job performance is, the more useful it can be [28]. Users may not feel confident with a new system, since they do not have the necessary skills and comfort. Nevertheless, after gaining a certain amount of knowledge and being more familiar with it, their perception of its ease of use may change [29]. If using B-flow USG is easy, people may not need to waste time to find out how to use them. Research in various fields has confirmed the significant effect of perceived ease of use on perceived usefulness [11, 18, 19, 25, 30]. Thus, it was hypothesized as follows:

\section{H7. Perceived ease of use has a positive relationship with perceived usefulness of B-flow USG.}

\section{Knowledge}

Understanding of a technology is considered to be a learned behavior according to the Theory of Reasoned Action [14]. Therefore, it ought to track the growth of knowledge via experimentation. Although several TAM studies evaluate user knowledge directly, there are many research have utilized experimentation to represent knowledge [31]. the following research mainly studies practical knowledge, through evaluating users' estimations of their individual comparative expertise with technology [32]. Earlier research has verified that the knowledge has a positive effect on perceived usefulness [33]. Therefore, it was hypothesized as follows:

\section{H8. Knowledge has a positive relationship with} perceived usefulness of B-flow USG.

\section{Methods}

\section{Survey design}

This study depends on information collected from Bflow USG users. A survey methodology was conducted to collect the data and to validate the conceptual model proposed in this research. The sample was drawn from the medical doctors including radiologists, urologists, gynecologists, pediatric surgeons.

The survey consisted of three parts. The first part included the cover letter and informed consent statement. The second part consisted of the questions related to demographics, such as age, gender, B-flow USG experience, etc.. The third part consisted of the questions related to the TAM and additional items assessing knowledge and social influence. The survey did not contain any personal information that could potentially specify the identity of a particular respondent.

\section{Data collection}

For the aim of the research, the data was collected through online surveys. The objective of the study and background on the research were provided to the participants, and they are encouraged to participate. So as to evaluate the acceptance of B-flow USG, a survey of all users was preferred.

A total of 528 surveys were collected from participants, and 512 of them were used in the analysis, which is adequate since, as a rule of thumb, the sample size required for factor analysis should be at least four or five times of the number of items [34]. Overall, $67.5 \%$ of the respondents were male, and the average age of the participants was 36.5 . Of the respondents, $59 \%$ of them is working at university hospitals and average B-flow USG experience is 6.2 years. The summary of demographic information of the participants is provided in Table 1.

\section{Measurement development}

The five-point Likert scale was utilized to measure the variables in this paper. There are 7 constructs with 32 items. The three items for the actual use (e.g., AU01 AU02, AU03) were taken from [35]. The construct attitude toward use was measured by four items (e.g., ATT01, ATT02, ATT03, ATT04) from [36]. The three items to measure the construct behavioral intention to use (e.g., BIU01, BIU02, BIU03) were taken from [36]. The construct knowledge was measured by three items (e.g., KNOW01, KNOW02, KNOW03) from [33]. The six items 
Table 1 Demographic information

\begin{tabular}{|c|c|c|}
\hline \multicolumn{3}{|l|}{ Age (years) } \\
\hline Max: 60 & Min: 26 & Avg: 36.5 \\
\hline \multicolumn{3}{|l|}{ Gender (\%) } \\
\hline Female: 32.5 & Male: 67.5 & \\
\hline \multicolumn{3}{|l|}{ Workplace (\%) } \\
\hline Private Hospital: 4.2 & $\begin{array}{l}\text { University } \\
\text { Hospital: } 59.5\end{array}$ & $\begin{array}{l}\text { Training and } \\
\text { Research } \\
\text { Hospital: } 22.2\end{array}$ \\
\hline \multicolumn{3}{|l|}{ Public Hospital: 14.1} \\
\hline \multicolumn{3}{|c|}{ Work experience as an MD (years) } \\
\hline Max: 35 & Min: 2 & Avg: 19.3 \\
\hline \multicolumn{3}{|c|}{ B-flow ultrasonography experience (\%) } \\
\hline Max: 10 & Min: 2 & Avg: 6.2 \\
\hline
\end{tabular}

for the construct perceived ease of use (e.g., PEU01, PEU2, ..., PEU06) were taken from $[8,16,36]$. The seven items to measure the construct perceived usefulness (e.g., PU01, PU02, ..., PU07) were taken from $[8,16,36]$. The six items for the construct social influence (e.g., SI01, SI02, ..., SI06) were taken from [36, 37]. The details of the constructs and items are provided in Table 2.

\section{Data analysis}

In this study, a multivariate analysis method, specifically, the partial least squares structural equation modeling (PLS-SEM), is used to test and validate the proposed model. This modeling approach enables researchers to explicate relatively new circumstance from measures and models even in the lack of theoretical background. The PLS-SEM, which was used in similar research in the literature, provides accurate estimations even the data is not normally distributed [38]. The SmartPLS 3.2.7 software was used to perform the PLS-SEM technique and the do the analyses.

\section{Results}

\section{Measurement model}

In order to test the measurement model's psychometric features, confirmatory factor analysis (CFA) was performed. The construct reliability and validity of the constructs were evaluated reviewing the content validity, convergent validity and discriminant validity of the constructs. The content validity was evaluated through corresponding literature and pilot testing the scale [39]. The convergent validity was assessed by item reliability of each measure, Cronbach's alpha, composite reliability (CR) of each construct and the average variance extracted (AVE) [39-41].

The item reliability of a measure is evaluated by its factor loadings which represent the correlation between each item and the respective construct. The recommended values for factor loadings is at least 0.6 [34, 41]. As provided in Table 3, the factor loadings of all the items are above 0.7 which proves convergent validity at the item level; therefore, none of the items had to be removed from the proposed research model. Moreover, the results show that all of the items have significant t-statistics $(p<0.05)$.

At the construct level, the reliability was evaluated by measuring the Cronbach's alpha and composite reliability values (Table 4). The Cronbach's alpha quantifies the level of internal consistency of constructs, and the higher is the better. It was suggested that Cronbach's alpha values above 0.7 should be considered good [41]. In this study, the Cronbach's alpha values of each construct exceed the threshold, which implies that each of the construct has a good internal consistency. The composite reliability denotes "the shared variance among a set of observed variables measuring an underlying construct" [41]; in other words, how well the items measure a construct. The CR values for the corresponding measures varied between 0.895 and 0.917 , exceeding the recommended value of 0.7 [41, 42].

Average variance extracted is the last measure of convergent validity; it indicates "the variance captured by the construct in relation to the amount of variance attributable to measurement error", and the recommended value for AVE is greater than $0.5[41,43]$. The results indicate that the AVE values of all constructs are greater than the recommended value 0.5 (Table 4). The statistical results imply good convergent validity of the measurement model.

Next, the discriminant validity was assessed which measures the extent to which constructs differ. Discriminant validity at the item level exists "when an item correlates more highly with items in the construct it purports to measure than items belonging to other constructs" [44, 45], which is also valid for this study. Discriminant validity of the measurement constructs are evaluated through "comparing the square root of the AVE for a given construct with the correlations between that construct and all other constructs" [46]. The correlation matrix for the constructs are provided in Table 5. Discriminant validity at the construct level appears satisfactory since the diagonal elements, square roots of the AVEs, are larger than the off-diagonal elements in their corresponding rows and columns.

\section{Structural model and hypotheses testing}

Structural equation modeling is performed to check the fit between the proposed research model and the data. The reason for applying this methodology is to observe several relationships simultaneously, particularly where there are direct and indirect effects among the constructs within the model [34]. 
Table 2 Constructs, codes, references and items

\begin{tabular}{|c|c|c|c|}
\hline Construct & $\begin{array}{l}\text { Item } \\
\text { Code }\end{array}$ & Reference & Items \\
\hline \multirow[t]{3}{*}{ Actual use } & AU1 & \multirow[t]{3}{*}[35]{} & "I use the B-flow USG very intensively (many hours per day, at work)" \\
\hline & AU2 & & "I use the B-flow USG very frequently (many times per day, at work)" \\
\hline & AU3 & & "Overall, I use the B-flow USG a lot" \\
\hline \multirow[t]{4}{*}{ Attitude toward use } & АТТ01 & \multirow[t]{4}{*}[36]{} & "Using the B-flow USG is a good idea." \\
\hline & АТТ02 & & "The B-flow USG makes work more interesting." \\
\hline & АТТ03 & & "Working with the B-flow USG is fun." \\
\hline & АТТ04 & & "I like working with the B-flow USG." \\
\hline \multirow{3}{*}{$\begin{array}{l}\text { Behavioral intention to } \\
\text { use }\end{array}$} & BIU01 & \multirow[t]{3}{*}{ [36] } & "I intend to use the B-flow USG in the next $<$ n > months." \\
\hline & BIU02 & & "I predict I would use the B-flow USG in the next $<$ n > months." \\
\hline & BIU03 & & "I plan to use the B-flow USG in the next $<$ n $>$ months." \\
\hline \multirow[t]{3}{*}{ Knowledge } & KNOW01 & \multirow[t]{3}{*}{ [33] } & "I have knowledge about the B-flow USG." \\
\hline & KNOW02 & & "I have knowledge about the benefits of the B-flow USG." \\
\hline & KNOW03 & & "I have knowledge about the B-flow USG know-how." \\
\hline \multirow[t]{6}{*}{ Perceived ease of use } & PEU01 & \multirow[t]{6}{*}[8,16,36]{} & "Learning to operate the B-flow USG would be easy for me." \\
\hline & PEU02 & & "I would find it easy to get the B-flow USG to do what I want it to do." \\
\hline & PEU03 & & "My interaction with the B-flow USG would be clear and understandable." \\
\hline & PEU04 & & "I would find the B-flow USG to be flexible to interact with." \\
\hline & PEU05 & & "It would be easy for me to become skillful at using the B-flow USG." \\
\hline & PEU06 & & "I would find the B-flow USG easy to use." \\
\hline \multirow[t]{7}{*}{ Perceived usefulness } & PU01 & \multirow[t]{7}{*}[8,16,36]{} & "Using the B-flow USG would improve my productivity." \\
\hline & PU02 & & "Using the B-flow USG would increase my efficiency in transaction." \\
\hline & PU03 & & "Using the B-flow USG would make my transaction easier." \\
\hline & PU04 & & "Using the B-flow USG would make my transaction quicker." \\
\hline & PU05 & & "I find the B-flow USG to be cost saving." \\
\hline & PU06 & & "I think the B-flow USG is valuable to me." \\
\hline & PU07 & & "Overall, I find the B-flow USG to be useful." \\
\hline \multirow[t]{6}{*}{ Social influence } & $\mathrm{SI} 01$ & \multirow[t]{6}{*}[36,37]{} & "People who influence my behavior think that I should use the B-flow USG." \\
\hline & $\mathrm{SIO} 2$ & & "People who are important to me think that I should use the B-flow USG." \\
\hline & $\mathrm{SIO3}$ & & "I use the B-flow USG because of the proportion of coworkers who use the B-flow USG." \\
\hline & $\mathrm{SIO4}$ & & $\begin{array}{l}\text { "People in my organization who use the B-flow USG have more prestige than those who do } \\
\text { not." }\end{array}$ \\
\hline & $\mathrm{S} 105$ & & "People in my organization who use the B-flow USG have a high profile." \\
\hline & $\mathrm{SI06}$ & & "Having the B-flow USG is a status symbol in my organization." \\
\hline
\end{tabular}

PLS-SEM through SmartPLS 3.2.7 was used in order to test the hypotheses. Non-parametric assessment criteria based on bootstrapping is performed with 5000 iterations of resampling $[47,48]$. Table 6 summarizes the standardized parameters ( $\beta$ coefficients) and the corresponding $t$-values to measure each coefficient's significance [38].

Behavioral intention to use significantly affects actual use of B-flow USG ( $\beta=0.673, p<0.05$; H1 supported). Social influence and attitude toward use significantly affect behavioral intention to use B-flow USG ( $\beta=0.445$, $p<0.05 ; \beta=0.435, p<0.05 ; \mathrm{H} 2$ and H3 supported); however, the effect of perceived usefulness on behavioral intention to use B-flow USG is found to be insignificant ( $\beta=0.036, p>0.05$; H4 not supported). Perceived usefulness significantly influences attitude toward use B-flow USG ( $\beta=0.611 p<0.05$; H5 supported); on the other hand, and perceived ease of use affects attitude toward use B-flow USG, but not significantly $(\beta=0.015, p>0.05$; H6 not supported). The effects of and perceived ease of use and knowledge on perceived usefulness are significant $(\beta=0.374, p<0.05 ; \beta=0.478, p<0.05 ; \mathrm{H} 7$ and $\mathrm{H} 8$ 
Table 3 Confirmatory factor analysis

\begin{tabular}{|c|c|c|c|c|c|}
\hline Construct & Item Code & Mean & Standard Deviation & Factor Loadings & T Statistics \\
\hline \multirow[t]{4}{*}{ Attitude toward use } & ATT01 & 0.922 & 0.005 & 0.922 & 185.473 \\
\hline & ATT02 & 0.814 & 0.014 & 0.813 & 59.105 \\
\hline & АТT03 & 0.774 & 0.017 & 0.773 & 46.311 \\
\hline & ATT04 & 0.801 & 0.015 & 0.802 & 54.936 \\
\hline \multirow[t]{3}{*}{ Actual use } & AU01 & 0.927 & 0.004 & 0.926 & 212.943 \\
\hline & $\mathrm{A} \cup 02$ & 0.834 & 0.013 & 0.833 & 63.876 \\
\hline & 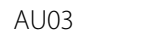 & 0.845 & 0.013 & 0.846 & 65.702 \\
\hline \multirow[t]{3}{*}{ Behavioral intention to use } & BIU01 & 0.933 & 0.004 & 0.933 & 233.299 \\
\hline & BIU02 & 0.836 & 0.011 & 0.837 & 73.593 \\
\hline & BIU03 & 0.856 & 0.011 & 0.857 & 80.727 \\
\hline \multirow[t]{3}{*}{ Knowledge } & KNOW01 & 0.925 & 0.004 & 0.924 & 220.230 \\
\hline & KNOW02 & 0.825 & 0.014 & 0.825 & 56.960 \\
\hline & KNOW03 & 0.830 & 0.015 & 0.830 & 53.583 \\
\hline \multirow[t]{6}{*}{ Perceived ease of use } & PEU01 & 0.924 & 0.004 & 0.924 & 221.790 \\
\hline & PEU02 & 0.784 & 0.017 & 0.784 & 46.833 \\
\hline & PEU03 & 0.783 & 0.016 & 0.783 & 48.758 \\
\hline & PEU04 & 0.767 & 0.018 & 0.767 & 42.854 \\
\hline & PEU05 & 0.758 & 0.018 & 0.758 & 42.149 \\
\hline & PEU06 & 0.770 & 0.017 & 0.770 & 44.367 \\
\hline \multirow[t]{7}{*}{ Perceived usefulness } & PU01 & 0.927 & 0.004 & 0.928 & 236.571 \\
\hline & PU02 & 0.749 & 0.017 & 0.749 & 43.990 \\
\hline & PU03 & 0.773 & 0.016 & 0.772 & 48.889 \\
\hline & PU04 & 0.742 & 0.017 & 0.743 & 43.684 \\
\hline & PU05 & 0.770 & 0.017 & 0.771 & 45.973 \\
\hline & PU06 & 0.751 & 0.017 & 0.749 & 43.880 \\
\hline & PU07 & 0.761 & 0.016 & 0.762 & 46.390 \\
\hline \multirow[t]{6}{*}{ Social influence } & $\mathrm{SI} 01$ & 0.927 & 0.004 & 0.927 & 222.203 \\
\hline & $\mathrm{S} 102$ & 0.744 & 0.017 & 0.746 & 42.618 \\
\hline & $\mathrm{SIO3}$ & 0.782 & 0.016 & 0.781 & 50.388 \\
\hline & $\mathrm{SIO4}$ & 0.730 & 0.019 & 0.731 & 39.198 \\
\hline & $\mathrm{S} 105$ & 0.765 & 0.017 & 0.766 & 44.741 \\
\hline & $\mathrm{S} 106$ & 0.777 & 0.016 & 0.777 & 49.935 \\
\hline
\end{tabular}

Table 4 Construct reliability and validity for the measurement model

\begin{tabular}{llll}
\hline Constrtuct & Cronbach's Alpha & Composite Reliability (CR) & Average Variance Extracted (AVE) \\
\hline ATT & 0.848 & 0.898 & 0.688 \\
AU & 0.839 & 0.903 & 0.756 \\
BIU & 0.849 & 0.909 & 0.769 \\
KNOW & 0.826 & 0.895 & 0.741 \\
PEU & 0.886 & 0.914 & 0.640 \\
PU & 0.894 & 0.917 & 0.615 \\
SI & 0.878 & 0.909 & 0.625 \\
\hline
\end{tabular}


Table 5 Discriminant validity for the measurement model

\begin{tabular}{llllllll}
\hline & ATT & AU & BIU & KNOW & PEU & PU & SI \\
\hline ATT & 0.830 & & & & & & \\
AU & 0.513 & 0.869 & & & & & \\
BIU & 0.675 & 0.673 & 0.877 & & & & \\
KNOW & 0.439 & 0.221 & 0.279 & 0.861 & & & \\
PEU & 0.348 & 0.187 & 0.217 & 0.458 & 0.800 & & \\
PU & 0.602 & 0.327 & 0.432 & 0.649 & 0.593 & 0.784 & \\
SI & 0.492 & 0.458 & 0.670 & 0.230 & 0.123 & 0.302 & 0.791 \\
\hline
\end{tabular}

supported). All the hypotheses which are supported or not are summarized in Table 7.

The $R$-square $\left(R^{2}\right)$ value specifies the percentage of total variance of the dependent variable (i.e., actual use) explained by the independent variables. Among the endogenous constructs, behavioral intention to use has the highest amount of variance accounted by its exogenous construct, $61 \%\left(R^{2}=0.607\right)$. The results further show that proposed model explains the $36 \%\left(R^{2}=0.363\right)$ of total variance of attitude toward use B-flow USG, $45 \%$ $\left(R^{2}=0.453\right)$ of total variance of actual use, $53 \%\left(R^{2}=\right.$ 0.532 ) of total variance of perceived usefulness, as provided in Table 8.

Figure 2 illustrates the $\beta$ coefficients and the $\mathrm{R}^{2}$ values of the dependent variables. The analysis implies that behavioral intention to use is a significant determinant of actual use of B-flow USG. It is shown that behavioral intention to use is explained by social influence and attitude toward use, which is consistent with the earlier literature; nevertheless, the effect of perceived usefulness on behavioral intention to use B-flow USG is found to be insignificant. Perceived usefulness significantly influences attitude toward use B-flow USG; on the other hand, in contrast to literature, perceived ease of use affects attitude toward use insignificantly. Finally, perceived ease of use and knowledge are found to be significant determinants of perceived usefulness.

\section{Direct and indirect effects}

Direct, indirect and total effects of each construct on the behavioral intention to use B-flow USG are provided in Table 9. Behavioral intention to use has the highest direct and total effect on actual use of B-flow USG. Attitude toward use, knowledge, perceived ease of use, perceived usefulness and social influence have significant indirect effects on actual use of B-flow USG.

Further comments for this research can be crucial to foster the whole concept. In this model, perceived usefulness and attitude toward use have intervening roles. In order to observe the relationships, new models are set up between perceived ease of use-attitude toward use and perceived usefulness-behavioral intention to use. So that, the role of perceived usefulness and attitude toward use will be seen in the implementation of extended technology acceptance model. According to the $p$-values provided in Figs. 3 and 4 there are significant relationships between perceived ease of use and attitude toward use, and perceived usefulness and behavioral intention to use, respectively.

Employment of PLS is to determine the effect of mediation, which is the strong relation between the predictor and criterion variable. In this paper, whether perceived usefulness and attitude toward use are the mediating variables or not are identified. As illustrated in Fig. 3, perceived ease of use has a significant direct effect on attitude toward use B-flow USG $(\beta=0.349, p<0.05)$. When perceived ease of use and perceived usefulness are regressed on attitude toward use, perceived ease of use became insignificant $(\beta=0.016, p>0.05)$, which is case in Fig. 3b. Hence, it can be concluded that perceived usefulness is a mediator.

Similarly, perceived usefulness has a significant direct effect on behavioral intention to use B-flow USG ( $\beta=$ $0.435, p<0.05$ ) (Fig. 4). When perceived usefulness and attitude toward use are regressed on behavioral intention to use B-flow USG, perceived usefulness became insignificant $(\beta=0.04, p>0.05)$, which is case in Fig. $4 \mathrm{~b}$.

Table 6 Path coefficients

\begin{tabular}{lllll}
\hline & $\begin{array}{l}\text { Standardized Path Coefficient } \\
(\beta \text { Coefficient) }\end{array}$ & Standard Deviation & T Statistics & $P$ Values \\
\hline ATT - > BIU & $0.435^{*}$ & 0.036 & 11.935 & 34.386 \\
BIU - > AU & $0.673^{*}$ & 0.020 & 17.316 & 0.000 \\
KNOW - > PU & $0.478^{*}$ & 0.028 & 0.312 & 0.000 \\
PEU - > ATT & 0.015 & 0.047 & 12.805 & 0.755 \\
PEU - > PU & $0.374^{*}$ & 0.029 & 17.147 & 0.000 \\
PU - > ATT & $0.611^{*}$ & 0.036 & 0.980 & 0.000 \\
PU - > BIU & 0.036 & 0.037 & 14.925 & 0.328 \\
SI - > BIU & $0.445^{*}$ & 0.030 & 0.000 \\
\hline
\end{tabular}

${ }^{\circ} p<0.05$ 
Table 7 Summary of hypotheses

\begin{tabular}{|c|c|c|c|}
\hline Hypothesis & Path & Hypothesis & Supported \\
\hline $\mathrm{H} 1$ & $\mathrm{BIU}->\mathrm{AU}$ & "Behavioral intention to use has a positive effect on actual use of B-flow USG." & Yes \\
\hline $\mathrm{H} 2$ & $\mathrm{SI}->\mathrm{BIU}$ & "Social influence has a positive effect on behavioral intention to use B-flow USG." & Yes \\
\hline $\mathrm{H} 3$ & $\mathrm{ATT}->\mathrm{BIU}$ & "Attitude toward use has a positive effect on behavioral intention to use B-flow USG." & Yes \\
\hline $\mathrm{H} 4$ & $P U->B I U$ & "Perceived usefulness has a positive effect on behavioral intention to use B-flow USG." & No \\
\hline H5 & $\mathrm{PU}->\mathrm{ATT}$ & "Perceived usefulness has a positive effect on attitude toward use B-flow USG." & Yes \\
\hline H6 & PEU- $>$ ATT & "Perceived ease of use has a positive effect on attitude toward use B-flow USG." & No \\
\hline $\mathrm{H} 7$ & $P E U->P U$ & "Perceived ease of use has a positive effect on perceived usefulness of B-flow USG." & Yes \\
\hline $\mathrm{H} 8$ & KNOW- $>$ PU & "Knowledge has a positive effect on perceived usefulness of B-flow USG." & No \\
\hline
\end{tabular}

Hence, it can be concluded that attitude toward use is a mediator.

\section{Discussion}

The early period of a radiological assessment of intense abdominal torment in the pediatric age gather caused by the contorted pedicle in ovarian torsion stays testing [49]. In the mid-1990s, most specialists recommended that the visual evaluation of contorted adnexial structures and color change in the ovaries pictured by exploratory laparotomy or a laparoscopic strategy is the best quality level for the choice to continue with the medical procedure [4]. Be that as it may, it was proposed that visual finding amid laparoscopy could be misdirecting [1]. Today, it is concurred that discoveries of clinical assessment, ultrasonography and attractive reverberation imaging (X-ray) help choice to continue with the medical procedure. The patient history and the palpation of a mass in the lower abdominal segment may propose the likelihood of torsion, however ultrasonography is imperative for the differential determination from other clinical pathologies [1]. The assessment of the veins in the hilus locale is trying in the non-intrusive radiological examination.

The color Doppler is generally utilized for the ultrasonographic assessment of the ovarian tissue and the veins, and as of late, B-flow USG gave tasteful outcomes to the appraisal of blood flow rate and speed [49, 50]. The sonographic window and ancient rarities are constraints in the assessment of veins with color Doppler USG in the intense stage, however these impediments were overwhelmed by utilizing B-flow USG $[7,51,52]$.

Table 8 R-Square values

\begin{tabular}{lll}
\hline & R-Square & R-Square (Adjusted) \\
\hline ATT & 0.363 & 0.360 \\
AU & 0.453 & 0.452 \\
BIU & 0.607 & 0.605 \\
PU & 0.532 & 0.530 \\
\hline
\end{tabular}

The proposed research model explains $45 \%$ of total variance of actual use of B-flow USG. A path analysis indicated that the majority results are consistent with the information system literature by showing that perceived usefulness, perceived ease of use, attitude toward use and behavioral intention to use are the significant determinants (direct or indirect) of actual use of B-flow USG. In addition to the TAM constructs, two external factors social influence and knowledge are also significant in predicting peoples' actual use of B-flow USG.

This study contributes to recent research that found behavioral intention to use to be key determinant of actual use of B-flow USG. Next, it has been shown that social influence and attitude toward use are significant factors affecting the behavioral intention to use B-flow USG. Moreover, perceived usefulness has significant effect on attitude toward use B-flow USG. The results of the proposed model highlights knowledge and perceived ease of use as significant factors influencing perceived usefulness of B-flow USG.

The current research also shows that perceived usefulness is not affecting behavioral intention to use significantly; however, it affects behavioral intention to use indirectly attitude toward use. Similarly, perceived ease of use is not a significant determinant of attitude toward use B-flow USG; however, it affects attitude toward use indirectly through perceived usefulness. In addition, perceived usefulness mediates the relationship between perceived ease of use and attitude toward use, and attitude toward use mediates the relationship between perceived usefulness and behavioral intention to use B-flow USG.

\section{Implications}

The findings of this research provide also useful inferences for stakeholders including B-flow USG users, hospital managers, investors, manufacturers and suppliers to recognize the perception toward the acceptance and adoption of B-flow USG. The decision makers need to recognize the constructs of the model that were tested in this paper. 


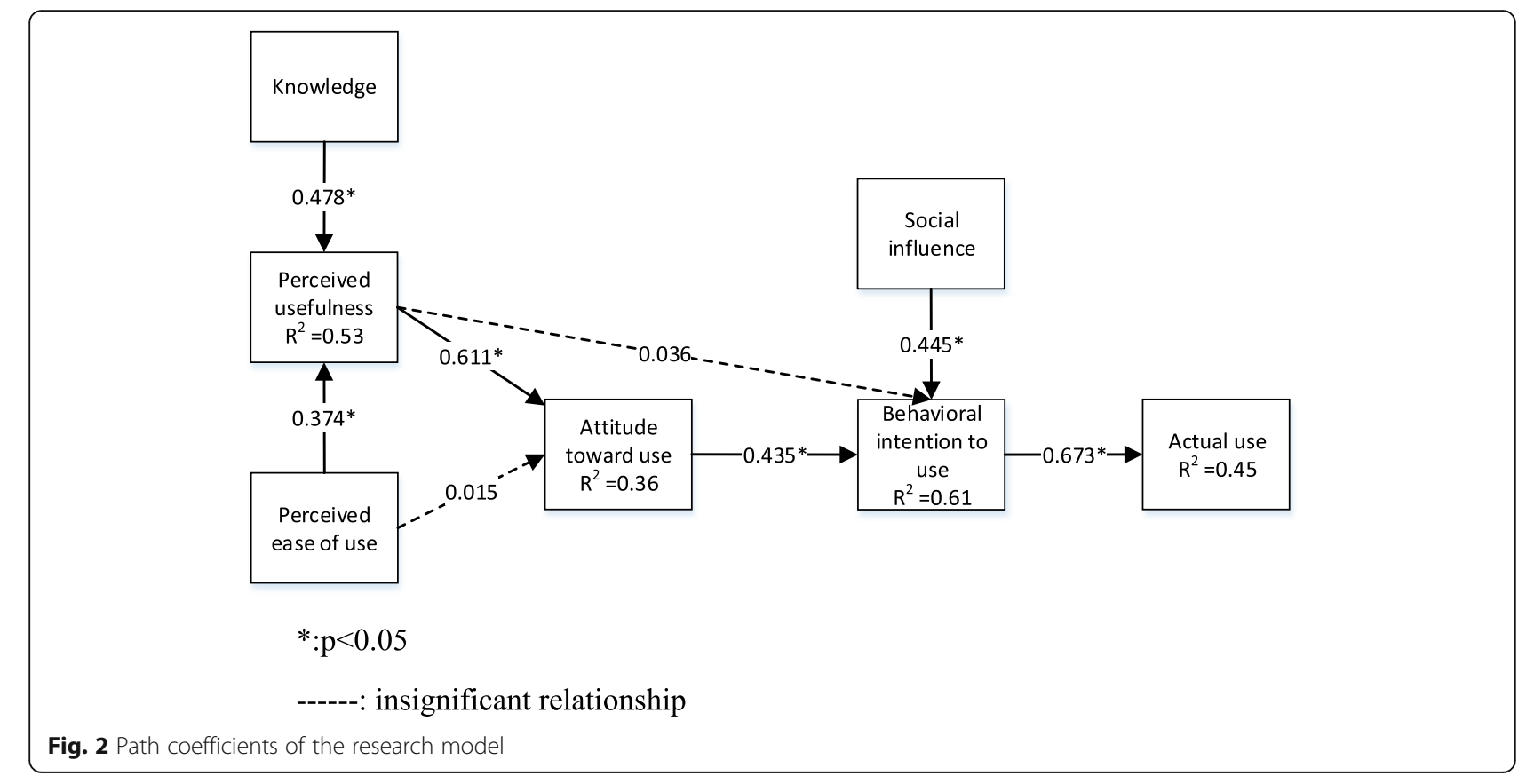

The most noticeable aspect of this model is that social influence, knowledge, perceived ease of use, perceived usefulness, attitude towards use and behavioral intention to use are determinants of actual use B-flow USG. Among them, behavioral intention to use and social influence have the strongest impact on actual use of Bflow USG.

Social influence has been found to be a significant indirect determinant of actual use B-flow USG. The opinions of colleagues and peers may be very important among the users of B-flow USG. The physicians, hospital managements and medical communities can take an optimistic position toward system adoption. If the B-flow USG users are appreciated for their system use, the potential users might be motivated to use the it.

Another noticeable aspect of the results is that knowledge, perceived ease of use and perceived usefulness has indirect effects on intention to use B-flow USG, which indicates that users tend to rate B-flow USG useful if they have knowledge about and find easy to use it. In other words, physicians are likely to use B-flow USG more if they believe that using the system will increase their performance and productivity. Therefore, for Bflow USG to be successful, developers need to focus their attention on sufficient training programs, designing not only useful but also easy to use.

\section{Limitations and future research directions}

Although the findings of the present study contribute to a better understanding of the factors that affect behavioral intention to use B-flow USG, there are several limitations to this study, which offers an opportunity for future research. Firstly, the current results cannot be generalized to the wider population due to the fact that the sample was obtained from physicians in Turkey. The findings might change if the model is retested in a different region. Any generalization of the results to other context should be made with caution although they are relatively reflecting the medical imaging technology. Secondly, demographic information that were collected

Table 9 Direct, indirect and total effects on actual use of B-flow USG

\begin{tabular}{|c|c|c|c|c|c|}
\hline $\begin{array}{l}\text { Dependent } \\
\text { Variable }\end{array}$ & $\begin{array}{l}\text { Independent } \\
\text { Variables }\end{array}$ & $\begin{array}{l}\text { Direct } \\
\text { Effects }\end{array}$ & $\begin{array}{l}\text { Indirect } \\
\text { Effects }\end{array}$ & $\begin{array}{l}\text { Total } \\
\text { Effects }\end{array}$ & $P$ Values \\
\hline \multirow[t]{6}{*}{ Actual use of B-flow USG } & ATT & - & $0.293^{*}$ & $0.293^{*}$ & 0.000 \\
\hline & BIU & $0.673^{*}$ & - & $0.673^{*}$ & 0.000 \\
\hline & KNOW & - & $0.097^{*}$ & $0.097^{*}$ & 0.000 \\
\hline & PEU & - & $0.072^{*}$ & $0.072^{*}$ & 0.000 \\
\hline & PU & - & $0.203^{*}$ & $0.203^{*}$ & 0.000 \\
\hline & $\mathrm{SI}$ & - & $0.300^{*}$ & $0.300^{*}$ & 0.000 \\
\hline
\end{tabular}


a

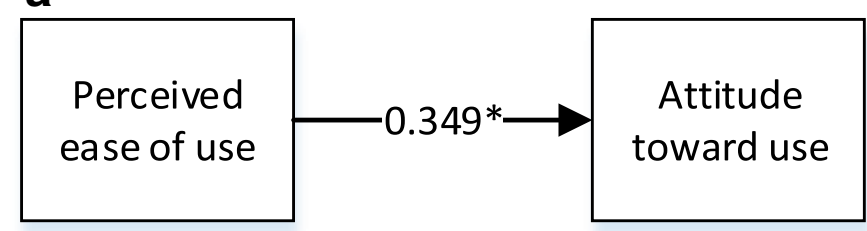

b

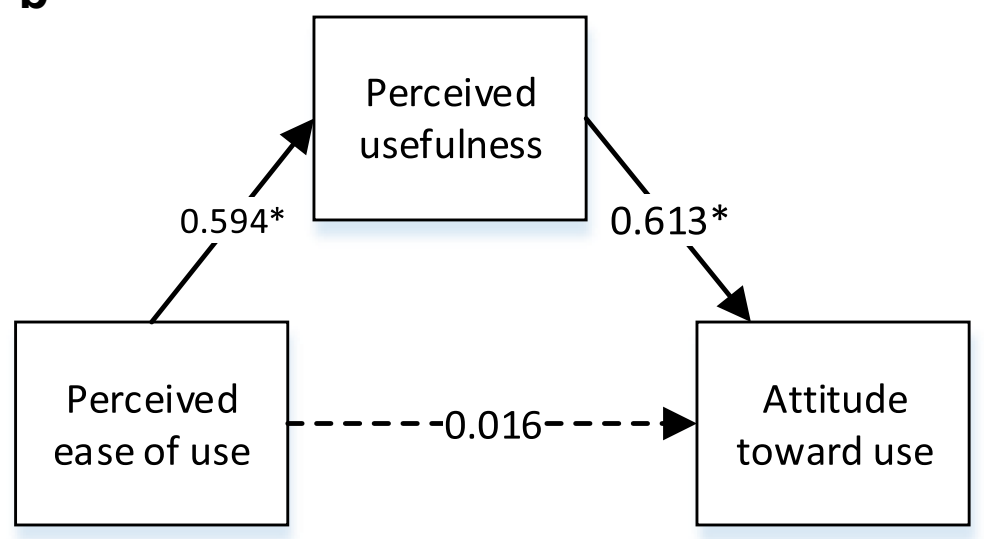

Fig. 3 a Standardized parameters of direct effects. b Standardized parameters of indirect effects (mediation effect of perceived usefulness)

a

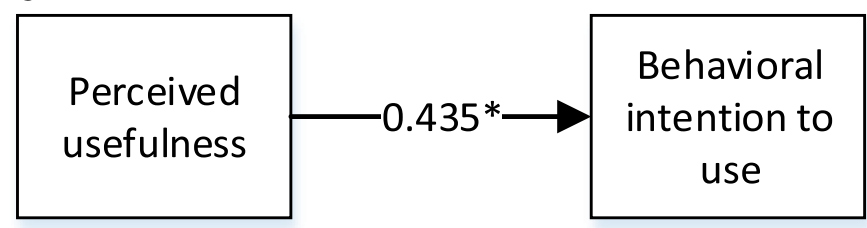

b

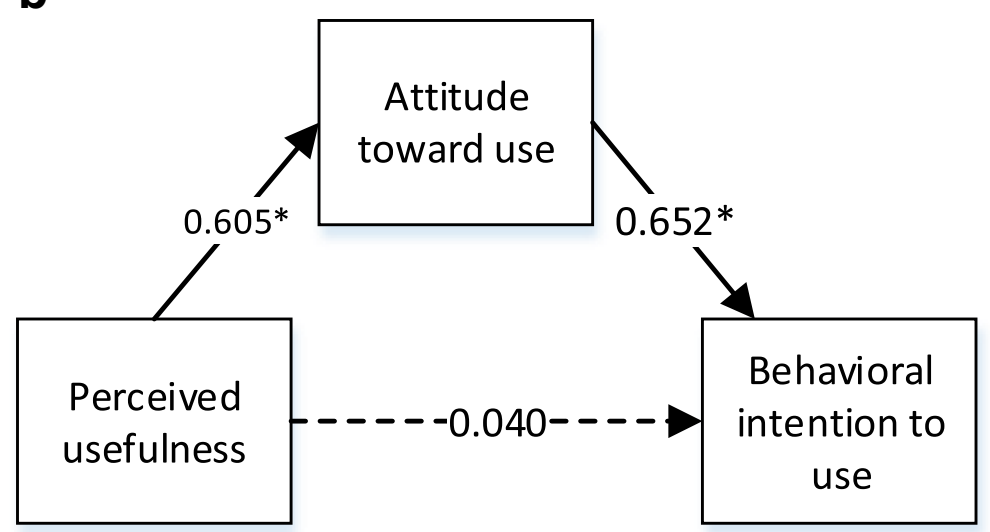

Fig. 4 a Standardized parameters of direct effects. b Standardized parameters of indirect effects (mediation effect of attitude toward use) 
through survey was not used as a factor in the proposed research model. As a future research, demographic characteristics including gender, age, education level or employment, can be incorporated in the model. Thirdly, even though some portion of the dependent variables are explained, $61 \%$ of behavioral intention to use is explained in the research model. Therefore, as a future research, further constructs may be taken into account that might be important in explaining behavioral intention to use B-flow USG. Lastly, this research can be integrated with qualitative study to understand and to explain the behavioral intention to use B-flow USG due to the fact that qualitative and quantitative aspects may complement each other to offer a better understanding.

\section{Conclusions}

This paper aims to investigate the acceptance of a medical imaging technology, B-flow USG using the Technology Acceptance Model as the main theoretical framework, and integrate key determinants, including knowledge and social influence. A total of 528 surveys were collected from the medical doctors including radiologists, urologists, gynecologists, pediatric surgeons between June and October 2018, and 512 of the surveys were used in the analysis. So as to investigate the proposed research model, structural equation modeling using partial least squares methodology was conducted, which is widely used in several disciplines. SmartPLS software was utilized to analyze the collected data. This study enables both practical and theoretical implications for B-flow USG use. To the best of knowledge, this study is the first comprehensive study to integrate the constructs mentioned above to examine the antecedents of B-flow USG acceptance.

\section{Abbreviations}

ATT: Attitude toward use; AU: Actual use; AVE: Average variance extracted; BIU: Behavioral intention to use; CFA: Confirmatory factor analysis; CR: Composite reliability; KNOW: Knowledge; PEU: Perceived ease of use; PLSSEM: Partial least squares structural equation modeling; PU: Perceived usefulness; SEM: Structural equation modeling; SI: Social influence;

TAM: Technology acceptance model; TRA: Theory of reasoned action; USG: Ultrasonography

\section{Acknowledgements}

Not applicable.

\section{Authors' contributions}

GHK was responsible for study design, data collection, analyzing the data, and preparing the manuscript. The author read and approved the final manuscript.

\section{Funding}

This research did not receive any specific funding or grants from funding agencies in the public, commercial, or not-for-profit sectors.

\section{Availability of data and materials}

The datasets used and analyzed during the current study are available from the corresponding author on reasonable request.
Ethics approval and consent to participate

Ethical approval was issued by the Social Sciences and Human Research Ethics Committee of the Istanbul Technical University (Project Number:79). Informed consent was obtained from all participants prior to the survey.

\section{Consent for publication}

Not applicable.

\section{Competing interests}

The author declares that she has no competing interest.

Received: 14 January 2019 Accepted: 30 June 2019

Published online: 12 July 2019

\section{References}

1. Hibbard LT. Adnexal torsion. Am J Obstet Gynecol. 1985;152(4):456-61 PubMed PMID: 4014339.

2. Rock J, Thompson J. Surgery for benign disease of the ovary. Oper Gynecol; 2003. p. 648-9.

3. Moravec WD, Angerman NS, Reale FR, Hajj SN. Torsion of the uterine adnexa: a clinicopathologic correlation. Int J Gynaecol Obstet. 1980;18(1):714 PubMed PMID: 6106607.

4. Baker TE, Copas PR. Adnexal torsion. A clinical dilemma. J Reprod Med. 1995:40(6):447-9 PubMed PMID: 7650658.

5. Başaklar AC. Bebek ve çocukların cerrahi ve ürolojik hastalıkları. Ankara: Palme Yayıncilik; 2006. p. 1765-86.

6. Chiao RY, Mo LY, Hall AL, Miller SC, Thomenius KE. B-mode blood flow (Bflow) imaging. Ultrason. 2000:1469-72 PubMed PMID: WOS: 000171881300323

7. Hançerlioğulları KÖ, Soyer T, Tosun A, Hançerlioğulları G. Is B-flow USG superior to color Doppler USG for evaluating blood flow patterns in ovarian torsion? J Pediatr Surg. 2015;50(7):1156-61.

8. Davis FD. Perceived usefulness, perceived ease of use, and user acceptance of information technology. MIS Q. 1989:319-40.

9. Ajzen I, Fishbein M. Attitude-behavior relations: a theoretical analysis and review of empirical research. Psychol Bull. 1977;84(5):888.

10. Nwankpa JK. ERP system usage and benefit: a model of antecedents and outcomes. Comput Hum Behav. 2015;45:335-44.

11. Venkatesh V, Davis FD. A theoretical extension of the technology acceptance model: four longitudinal field studies. Manag Sci. 2000;46(2): 186-204.

12. Ajzen I, Fishbein M. Understanding attitudes and predicting social behaviour; 1980

13. Azen I, Madden T. Prediction of goal directed behaviour: attitudes, intentions and perceived behavioural control; 1986.

14. Fishbein M, Aizen I. Belief, attitude, intention and behavior: an introduction to theory and research 1975.

15. Karaali D, Gumussoy CA, Calisir F. Factors affecting the intention to use a web-based learning system among blue-collar workers in the automotive industry. Comput Hum Behav. 2011;27(1):343-54.

16. Davis FD, Bagozzi RP, Warshaw PR. User acceptance of computer technology: a comparison of two theoretical models. Manag Sci. 1989;35(8): 982-1003.

17. Ahn T, Ryu S, Han I. The impact of web quality and playfulness on user acceptance of online retailing. Inf Manag. 2007;44(3):263-75.

18. Calisir F, Altin Gumussoy C, Bayram A. Predicting the behavioral intention to use enterprise resource planning systems: an exploratory extension of the technology acceptance model. Manag Res News. 2009;32(7):597-613.

19. Lee $M-C$. Factors influencing the adoption of internet banking: an integration of TAM and TPB with perceived risk and perceived benefit Electron Commer Res Appl. 2009;8(3):130-41.

20. Teo T, Noyes J. An assessment of the influence of perceived enjoyment and attitude on the intention to use technology among pre-service teachers: a structural equation modeling approach. Comput Educ. 2011;57(2):1645-53.

21. Mahindroo A, Singh H, Samalia HV. AWERProcedia Information Technology \& Computer Science. World. 2012;14:16

22. Pavlou PA. Consumer acceptance of electronic commerce: integrating trust and risk with the technology acceptance model. Int J Electron Commer. 2003;7(3):101-34. 
23. Venkatesh V. Determinants of perceived ease of use: integrating control, intrinsic motivation, and emotion into the technology acceptance model. Inf Syst Res. 2000;11(4):342-65.

24. Venkatesh $\mathrm{V}$, Morris MG. Why don't men ever stop to ask for directions? Gender, social influence, and their role in technology acceptance and usage behavior. MIS Q. 2000:115-39.

25. Lin W-B. Investigation on the model of consumers' perceived risk—integrated viewpoint. Expert Syst Appl. 2008;34(2):977-88.

26. Liu S-H, Liao H-L, Pratt JA. Impact of media richness and flow on e-learning technology acceptance. Comput Educ. 2009;52(3):599-607.

27. Arasanmi CN, Wang WYC, Singh H. Examining the motivators of training transfer in an enterprise systems context. Enterp Inf Syst. 2017;11(8): 1154-72.

28. Davis FD. User acceptance of information technology: system characteristics, user perceptions and behavioral impacts. Int J Man Mach Stud. 1993;38(3): 475-87.

29. Hackbarth G, Grover V, Mun YY. Computer playfulness and anxiety: positive and negative mediators of the system experience effect on perceived ease of use. Inf Manag. 2003;40(3):221-32.

30. Oh S, Ahn J, Kim B. Adoption of broadband internet in Korea: the role of experience in building attitudes. J Inf Technol. 2003;18(4):267-80.

31. Agarwal R, Prasad J. Are individual differences germane to the acceptance of new information technologies? Decis Sci. 1999;30(2):361-91.

32. Venkatesh $\mathrm{V}$, Davis FD. A model of the antecedents of perceived ease of use: development and test. Decis Sci. 1996;27(3):451-81.

33. Kumpajaya A, Dhewanto W. The acceptance of bitcoin in Indonesia: extended TAM with IDT. J Bus Manag. 2015;4(1):28-38.

34. Hair JF, Black WC, Babin BJ, Anderson RE, Tatham RL. Multivariate data analysis (Vol. 6). Upper Saddle River, NJ: Pearson Prentice Hall; 2006.

35. Elkhani N, Soltani S, Nazir Ahmad M. The effects of transformational leadership and ERP system self-efficacy on ERP system usage. J Enterp Inf Manag. 2014:27(6):759-85. https://doi.org/10.1108/JEIM-06-2013-0031.

36. Venkatesh V, Morris MG, Davis GB, Davis FD. User acceptance of information technology: toward a unified view. MIS Q. 2003:425-78.

37. Moore GC, Benbasat I. Development of an instrument to measure the perceptions of adopting an information technology innovation. Inf Syst Res. 1991;2(3):192-222.

38. Hair JF, Sarstedt M, Ringle CM, Mena JA. An assessment of the use of partial least squares structural equation modeling in marketing research. J Acad Mark Sci. 2012:40(3):414-33.

39. Sheikh Z, Islam T, Rana S, Hameed Z, Saeed U. Acceptance of social commerce framework in Saudi Arabia. Telematics Inform. 2017;34(8):1693-708.

40. Anderson JC, Gerbing DW. Assumptions and comparative strengths of the two-step approach: comment on Fornell and Yi. Sociol Methods Res. 1992; 20(3):321-33.

41. Fornell C, Larcker DF. Evaluating structural equation models with unobservable variables and measurement error. J Mark Res. 1981:39-50.

42. Peterson RA, Kim Y. On the relationship between coefficient alpha and composite reliability. J Appl Psychol. 2013:98(1):194

43. Fisher MT. A theory of viral growth of social networking sites: Case Western Reserve University; 2013.

44. Barclay D, Higgins C, Thompson R. The partial least squares (pls) approach to casual modeling: Personal Computer Adoption Ans Use as an Illustration 1995.

45. Kwok D, Yang S. Evaluating the intention to use ICT collaborative tools in a social constructivist environment. Int J Educ Technol High Educ. 2017;14(1):32.

46. Baharum HIB. Learning business English in virtual worlds: effectiveness and acceptance in a Malaysian context: a thesis submitted in partial fulfilment of the requirements for the degree of doctor of philosophy in management information Systems at Massey University. Palmerston North: Massey University; 2013

47. Chin WW. Commentary: issues and opinion on structural equation modeling: JSTOR; 1998

48. Henseler J, Ringle CM, Sinkovics RR. The use of partial least squares path modeling in international marketing. New challenges to international marketing: Emerald Group Publishing Limited; 2009. p. 277-319.

49. De Rosa P, Russo E, Cerbone V. Post-tx renal monitoring with B-flow ultrasonography. In: Kidney transplantation-new perspectives: InTech; 2011

50. Shadinger LL, Andreotti RF, Kurian RL. Preoperative sonographic and clinical characteristics as predictors of ovarian torsion. J Ultrasound Med. 2008;27(1): 7-13.
51. Servaes S, Zurakowski D, Laufer MR, Feins N, Chow JS. Sonographic findings of ovarian torsion in children. Pediatr Radiol. 2007;37(5):446-51.

52. Wang YH, Zheng QC, Yuan GX, Ren JH. The application of ultrasound B-flow imaging in detection of carotid atherosclerotic micro-vessel with ischemic cerebrovascular disease. Saudi Med J. 2012;33(10):1080-6.

\section{Publisher's Note}

Springer Nature remains neutral with regard to jurisdictional claims in published maps and institutional affiliations.
Ready to submit your research? Choose BMC and benefit from:

- fast, convenient online submission

- thorough peer review by experienced researchers in your field

- rapid publication on acceptance

- support for research data, including large and complex data types

- gold Open Access which fosters wider collaboration and increased citations

- maximum visibility for your research: over $100 \mathrm{M}$ website views per year

At BMC, research is always in progress.

Learn more biomedcentral.com/submissions 